\title{
Dietary change after smoking cessation: a prospective study
}

\author{
BY R. L. THOMPSON, ${ }^{1 *}$ S. D. M. PYKE, ${ }^{2}$ E. A. SCOTT, ${ }^{1}$ S. G. THOMPSON ${ }^{2}$ AND \\ D. A. WOOD \\ ${ }^{1}$ Preventive Cardiology, Department of Medicine, University of Southampton, Royal South Hants \\ Hospital, Southampton SO9 4PE \\ ${ }^{2}$ Medical Statistics Unit, London School of Hygiene and Tropical Medicine, University of London, \\ London WC1E 7HT \\ ${ }^{3}$ Clinical Epidemiology, National Heart and Lung Institute, University of London, \\ London SW3 $6 L Y$
}

(Received 11 August 1994 - Revised 10 November 1994 - Accepted 7 December 1994)

\begin{abstract}
A population sample of 375 men and women cigarette smokers were recruited to take part in a prospective study of smoking cessation to test the hypothesis that stopping smoking is associated with an increased consumption of the essential fatty acid linoleic acid, which explains the concomitant reduction in risk of coronary heart disease. Diet was assessed using a $10 \mathrm{~d}$ weighed record in 301 smokers at baseline, 153 at 4-month follow-up, of whom twenty-six had quit smoking, and 122 at 1-year followup, of whom twenty had quit. Compared with continuing smokers, those who had quit at the 4-month follow-up (mean 10 and 13 weeks for men and women respectively) had statistically significant increases in body weight ( $5 \%)$, energy intake $(13 \%)$, total dietary fat $(24 \%)$, all specific types of dietary fat $(26 \%$ polyunsaturated fat, $26 \%$ linoleic acid, $30 \%$ eicosapentaenoic acid, $23 \%$ monounsaturated fat and $22 \%$ saturated fat) and vitamin $E$ intake (19\%). The foods which appeared to contribute to increases in energy and fat intakes at the 4-month follow-up were vegetable oils and polyunsaturated margarines, processed meats and meat pies. By follow-up at 1 year (mean time since quitting 31 and 41 weeks for men and women respectively) there were no detectable differences in energy and total fat intakes. However, intakes of eicosapentaenoic acid and pteroylglutamate (folate) were statistically significantly higher in the quitters compared with the continuing smokers (37\% for eicosapentaenoic acid and $16 \%$ for folate). We conclude that the short-term increase in dietary intake of linoleic acid, which is not sustained by 1 year, cannot explain the reduction in risk of coronary disease following smoking cessation.
\end{abstract}

CHD risk: Linoleic acid intake: Smoking

Middle-aged cigarette smokers have a two- to threefold increase in risk of coronary heart disease (CHD) compared with life-long non-smokers, and those who quit smoking experience a reduction in the excess risk of $\mathrm{CHD}$, approaching $50 \%$ within 5 years in some studies (Cook et al. 1986; Doll et al. 1994) compared with those who continue to smoke. One explanation for the decrease in risk of CHD observed after smoking cessation is that cigarette smoking affects food choice and nutrient intake. Cross-sectional data show that cigarette smokers consume diets different from those of people who do not smoke (Fehily et al. 1984; Fulton et al. 1988; Subar et al. 1990; Whichelow et al. 1991; Margetts \& Jackson, 1993). Smoking cigarettes is associated with a different food pattern and altered nutrient intake, in particular more saturated fat, less polyunsaturated fat and a lower consumption of antioxidant vitamins (Thompson et al. 1992). Linoleic acid, an essential fatty acid and the major constituent of polyunsaturated fat in the diet, is inversely

* Present address: Institute of Public Health Medicine, University of Southampton, Level B, South Academic Block, Southampton General Hospital, Southampton SO16 6YD. 
associated with risk of CHD, with those developing the disease consuming less and having a lower proportion in adipose and other tissues (Wood \& Oliver, 1992). The increased risk of CHD in cigarette smokers may be partly explained by their less healthy diet and in particular a lower intake of linoleic acid. To investigate the relationship between cigarette smoking and dietary habits, a prospective study was carried out in which members of a group of smokers were encouraged to stop smoking, and those who quit smoking were then compared with those who continued to smoke. The hypothesis being tested was that quitting smoking is associated with an increase in the consumption of linoleic acid which might explain, at least in part, the concomitant reduction in risk of CHD in ex-smokers.

\section{SUBJECTS AND METHODS}

A population sample of 375 men and women cigarette smokers living in Southampton, aged between 40 and 59 years, were recruited through the Preventive Cardiology Clinic (Royal South Hants Hospital) between January 1990 and June 1991 to take part in a smoking cessation study. Recruitment methods have been described previously (Thompson et al. 1993). Briefly, 207 smokers were recruited by means of advertisements in the local press requesting the help of smokers who wished to stop smoking and 168 were randomly recruited from general practices; for the latter, smoking status was determined by postal questionnaire. Response rates for attendance were $61 \%$ for the randomly recruited smokers and $79 \%$ for the volunteers. A cross-sectional study in Scotland (Fulton et al. 1988) observed a $3.5 \mathrm{~g}$ lower dietary intake of linoleic acid in smokers compared with nonsmokers. Assuming that $80 \%$ of the smokers would complete the 1 year follow-up and that $20 \%$ would have quit smoking, a sample size at recruitment of 375 would mean that 300 were followed up and that sixty would have quit; this would give $99 \%$ power to detect a longitudinal average difference between quitters and continuing smokers of $3.5 \mathrm{~g} / \mathrm{d}$ at a $5 \%$ level of significance. At recruitment dietary intake was assessed using a $10 \mathrm{~d}$ weighed record. Subjects were instructed on how to weigh and record all items of food and drink consumed over $10 \mathrm{~d}$ (seven weekdays and three weekend days). Subjects were provided with digital scales (Soehnle 8000) and food-recording and instruction booklets. Items consumed outside the home were recorded in household measures. The record was checked for completeness when the subject returned approximately 2 weeks later. Subjects were also requested to attend follow-up appointments at 4 months and 1 year when they were encouraged to complete further weighed records.

All subjects were encouraged to stop smoking. For those smokers who did not wish to try on their own, smoking cessation classes were run by a research nurse (E.S.) who was trained in smoking cessation techniques, and consisted of a group of eight to ten smokers meeting once a week for 5 weeks. At the end of the course, follow-up (reunion) sessions were planned as desired. Dietary advice is often given during smoking cessation classes, but for the present study no formal dietary advice was given. Although other methods of smoking cessation were not advocated, a few subjects did undergo hypnosis or used Nicorette chewing gum.

The data from the dietary records were converted to nutrient intakes using Comp-eat version 4 (1991; Lifeline Nutritional Services Limited, London). To assess change in food choices the food items were grouped as follows: (1) foods rich in polyunsaturated fat, vegetable oils and sunflower/soya bean margarines; (2) foods rich in saturated fat, butter, ordinary margarines and lard; (3) processed meats and pies, bacon, sausages, meat pies and pasties, and sausage rolls; (4) meat, lamb, beef, pork and chicken; (5) fruit, fresh apples, oranges, pears and bananas; (6) vegetables, green vegetables and salad; (7) biscuits and chocolate, chocolate and plain and sweet biscuits; (8) whole milk and (9) low-fat milks, skimmed and semi-skimmed milks. 
Table 1. General characteristics and daily energy and nutrient intakes at baseline for men and women smokers

(Mean values with their standard errors)

\begin{tabular}{|c|c|c|c|c|}
\hline & \multicolumn{2}{|c|}{ Men } & \multicolumn{2}{|c|}{ Women } \\
\hline & Mean & $\mathbf{S E}$ & Mean & $\mathrm{SE}$ \\
\hline$n$ & \multicolumn{2}{|c|}{122} & \multicolumn{2}{|c|}{179} \\
\hline Age (years) & $49 \cdot 7$ & 0.5 & $49 \cdot 9$ & 0.5 \\
\hline$\%$ Non-manual occupations* & 47 & 5 & 51 & 4 \\
\hline Cigarettes $/ \mathrm{d} \dagger$ & $24 \cdot 3$ & $1 \cdot 1$ & $19 \cdot 5$ & 0.7 \\
\hline Height (m) & 1.75 & 0.01 & 1.62 & 0.01 \\
\hline Body weight (kg) & $78 \cdot 5$ & $1 \cdot 1$ & $65 \cdot 4$ & 0.9 \\
\hline Energy (MJ) & $10 \cdot 1$ & 0.2 & $7 \cdot 0$ & $0 \cdot 1$ \\
\hline Total fat $(\mathrm{g})$ & 98.8 & 1.9 & $72 \cdot 8$ & $1 \cdot 7$ \\
\hline PUFA (g) & $16 \cdot 2$ & 0.5 & $11 \cdot 3$ & $0 \cdot 3$ \\
\hline LA (g) & 11.8 & 0.5 & $7 \cdot 9$ & $0 \cdot 3$ \\
\hline EPA (g) & $0 \cdot 28$ & 0.02 & 0.23 & 0.01 \\
\hline MUFA (g) & $34 \cdot 9$ & 0.8 & $25 \cdot 3$ & 0.6 \\
\hline SFA (g) & 39.6 & 0.9 & $30 \cdot 1$ & 0.8 \\
\hline Ascorbic acid (mg) & $57 \cdot 8$ & 3.0 & 54.9 & $2 \cdot 5$ \\
\hline Vitamin $\mathrm{E}(\mathrm{mg})$ & $6 \cdot 6$ & 0.2 & $4 \cdot 9$ & 0.2 \\
\hline Pteroylglutamate (folate) $(\mu \mathrm{g})$ & 252 & 7 & 191 & 5 \\
\hline
\end{tabular}

PUFA, polyunsaturated fat; LA, linoleic acid; EPA, eicosapentaenoic acid; MUFA, monounsaturated fat; SFA, saturated fat.

* Does not include seven men and eight women whose social class was either unclassifiable or unknown.

$\uparrow$ Does not include nineteen men who rolled their own cigarettes using pipe tobacco.

Validation of reported smoking status at baseline and follow-up was by serum cotinine measurement. Seven subjects at 4-month follow-up and three subjects at the 1-year followup who reported quitting smoking used Nicorette chewing gum and reported smoking status was confirmed by breath $\mathrm{CO}$ measurement. Validation of reported quitting was accepted for cotinine $<14 \mathrm{ng} / \mathrm{ml}$ or $\mathrm{CO}<10 \mathrm{ppm}$ as appropriate. Where a reported quitter was not able to satisfy these criteria, he/she was assumed to be a continuing smoker. Where validation was not possible due to lack of cotinine or $\mathrm{CO}$ measurements as appropriate the individual concerned was eliminated from the relevant analyses. At the 4-month follow-up among the reported continuing smokers, one had switched to smoking a pipe and one to smoking cigars. At the 1-year follow-up, all those who reported continuing to smoke still smoked cigarettes. Social class was classified by longest occupation coded from Classification of Occupations of the UK Office of Populations, Censuses and Surveys (1980). Non-manual occupations were grouped as I, II, IIINM and manual occupations as IIIM, IV, V. Married women were classified by their husband's occupation and single women by their own occupation. Height and body weight were measured in indoor clothing with jacket and shoes removed.

\section{Statistical analysis}

Mean changes in intakes of nutrients were calculated separately for men and women, for continuing smokers and quitters. The strengths of the relationships between changes in nutrient intake and smoking group were assessed by regression analysis after adjusting for age, sex and occupational group (manual/non-manual) as necessary. Subsequently, nutrient changes were also adjusted for change in energy inclusive of energy from alcohol. 
Table 2. Changes in body weight and daily energy and nutrient intakes between baseline and 4-month follow-up, by smoking status and sex

(Mean values with their standard errors; negative values indicate that the mean was lower at follow-up)

\begin{tabular}{|c|c|c|c|c|c|}
\hline & \multicolumn{2}{|c|}{ Continuing smokers } & \multicolumn{2}{|c|}{ Quitters } & \multirow[b]{2}{*}{$P$ value } \\
\hline & Men & Women & Men & Women & \\
\hline$n \dagger$ & 52 & 71 & 12 & 14 & \\
\hline Body weight (kg) & 0.6 & 0.6 & $3 \cdot 9$ & $4 \cdot 3$ & $<0.0001$ \\
\hline $\mathrm{SE}$ & 0.3 & 0.2 & 0.9 & $1 \cdot 3$ & \\
\hline Energy (kJ) & -569 & -468 & 1240 & 287 & 0.0007 \\
\hline $\mathrm{SE}$ & 205 & 143 & 568 & 319 & \\
\hline Total fat (g) & $-6 \cdot 2$ & $-7 \cdot 3$ & $20 \cdot 8$ & $6 \cdot 1$ & $<0.0001$ \\
\hline SE & $2 \cdot 6$ & $2 \cdot 1$ & $8 \cdot 6$ & $4 \cdot 5$ & \\
\hline PUFA (g) & -0.7 & $-1 \cdot 1$ & $5 \cdot 0$ & 0.9 & 0.0002 \\
\hline $\mathrm{SE}$ & 0.7 & 0.4 & 1.8 & $0 \cdot 5$ & \\
\hline LA (g) & $-0 \cdot 2$ & -0.7 & $4 \cdot 2$ & 0.5 & 0.004 \\
\hline $\mathrm{SE}$ & 0.6 & 0.3 & $1 \cdot 6$ & 0.6 & \\
\hline EPA (g) & -0.03 & -0.05 & 0.04 & 0.02 & 0.03 \\
\hline SE & $0-03$ & 0.02 & $0 \cdot 13$ & 0.03 & \\
\hline MUFA (g) & $-2 \cdot 6$ & $-2 \cdot 6$ & $7 \cdot 2$ & 1.6 & 0.0007 \\
\hline SE & $1 \cdot 0$ & 0.8 & $3 \cdot 2$ & $1 \cdot 7$ & \\
\hline SFA (g) & $-2 \cdot 8$ & $-3 \cdot 3$ & $5 \cdot 8$ & $2 \cdot 1$ & 0.002 \\
\hline SE & $1 \cdot 1$ & $1 \cdot 0$ & $3 \cdot 5$ & $2 \cdot 2$ & \\
\hline Ascorbic acid (mg) & $2 \cdot 6$ & -0.9 & $-3 \cdot 5$ & $-5 \cdot 5$ & 0.2 \\
\hline $\mathbf{S E}$ & $3-7$ & $3 \cdot 5$ & $7 \cdot 0$ & $5 \cdot 0$ & \\
\hline Vitamin E (mg) & $-0 \cdot 3$ & $-0 \cdot 6$ & $1 \cdot 3$ & $0 \cdot 1$ & 0.01 \\
\hline SE & $0 \cdot 3$ & $0 \cdot 2$ & 0.7 & $0 \cdot 3$ & \\
\hline Pteroylglutamate (folate) $(\mu \mathrm{g})$ & $-1 \cdot 0$ & 1.8 & $16-3$ & $6 \cdot 9$ & 0.7 \\
\hline SE & $6 \cdot 6$ & $5 \cdot 8$ & $13 \cdot 3$ & $8 \cdot 1$ & \\
\hline
\end{tabular}

PUFA, polyunsaturated fat; LA, linoleic acid; EPA, eicosapentaenoic acid; MUFA, monounsaturated fat; SFA, saturated fat.

* Unadjusted $\boldsymbol{P}$ value for testing difference between mean changes in continuing smokers and quitters (pooled over men and women).

$\dagger$ Four subjects were unclassifiable due to missing data: three missing questionnaires and one missing cotinine and $\mathrm{CO}$.

Untransformed mean values with their standard errors are presented in the tables. The distributions of some nutrient changes were not normal. A log-transformation was used for the statistical analysis of all nutrients, after which the distributions of all nutrients were approximately symmetrical. For food groups the data did not approximate normality even after transformation and therefore data were expressed as medians and a non-parametric test (Wilcoxon Rank Sum) was used.

\section{RESULTS}

In total 301 of the $375(80 \%)$ cigarette smokers recruited to the study completed a baseline weighed record. The mean periods to follow-up were 4.6 (SD 0.9) months (4-month followup) and 12.7 (SD 1.6) months (1-year follow-up). At 4 months, 153 (51\%) of the 301 baseline smokers returned and completed a second weighed record and of these twentyeight claimed to have quit. On the basis of cotinine and $\mathrm{CO}$ measurements twenty-six of the reported quitters were confirmed as genuine quitters with two subjects reclassified as continuing smokers. At 1 year $122(41 \%)$ of the baseline smokers returned and completed a further weighed record, with twenty-two claiming to have quit; twenty of these were 
Table 3. Changes in body weight and daily energy and nutrient intakes between baseline and 1-year follow-up, by smoking status and sex

(Mean values with their standard errors; negative values indicate that the mean was lower at follow-up)

\begin{tabular}{|c|c|c|c|c|c|}
\hline & \multicolumn{2}{|c|}{ Continuing smokers } & \multicolumn{2}{|c|}{ Quitters } & \multirow[b]{2}{*}{$P$ value* } \\
\hline & Men & Women & Men & Women & \\
\hline$n \dagger$ & 38 & 63 & 8 & 12 & \\
\hline Body weight $\ddagger$ (kg) & 0.6 & 0.7 & $5 \cdot 3$ & $5 \cdot 5$ & $<0.0001$ \\
\hline $\mathrm{SE}$ & 0.4 & 0.4 & 1.6 & $1 \cdot 7$ & \\
\hline Energy $(\mathbf{k J})$ & -244 & -254 & 521 & -326 & 0.4 \\
\hline SE & 242 & 213 & 415 & 292 & \\
\hline Total fat (g) & $-4 \cdot 0$ & $-3 \cdot 5$ & $4 \cdot 1$ & -8.7 & 0.9 \\
\hline SE & $3 \cdot 1$ & $2 \cdot 9$ & $7 \cdot 8$ & $5 \cdot 0$ & \\
\hline PUFA (g) & $-0 \cdot 7$ & $-0 \cdot 2$ & $3 \cdot 6$ & $-1 \cdot 7$ & $0 \cdot 5$ \\
\hline $\mathbf{S E}$ & 0.8 & 0.5 & $2 \cdot 4$ & $1 \cdot 2$ & \\
\hline LA (g) & -0.3 & 0.2 & $2 \cdot 7$ & $-1 \cdot 7$ & 0.8 \\
\hline $\mathbf{S E}$ & 0.7 & $0 \cdot 5$ & $2 \cdot 3$ & $1 \cdot 1$ & \\
\hline $\mathrm{EPA}(\mathrm{g})$ & -0.04 & -0.07 & 0.04 & 0.02 & 0.03 \\
\hline SE & 0.03 & 0.03 & 0.05 & 0.05 & \\
\hline MUFA (g) & $-2 \cdot 4$ & $-1 \cdot 5$ & $0 \cdot 9$ & $-2 \cdot 3$ & 0.7 \\
\hline $\mathrm{SE}$ & $1 \cdot 2$ & $1 \cdot 2$ & $2 \cdot 7$ & 1.7 & \\
\hline SFA (g) & $-1 \cdot 3$ & $-1 \cdot 8$ & $-1 \cdot 1$ & $-5 \cdot 0$ & $0 \cdot 8$ \\
\hline SE & $1 \cdot 3$ & $1 \cdot 3$ & $3 \cdot 3$ & $2 \cdot 3$ & \\
\hline Ascorbic acid (mg) & $-3 \cdot 4$ & $1 \cdot 0$ & $-10 \cdot 9$ & $5 \cdot 6$ & 0.8 \\
\hline $\mathrm{SE}$ & $3 \cdot 1$ & $4 \cdot 2$ & $9 \cdot 1$ & $8 \cdot 2$ & \\
\hline Vitamin $\mathbf{E}(\mathrm{mg})$ & -0.4 & $-0 \cdot 2$ & 0.6 & $-0 \cdot 8$ & 0.8 \\
\hline SE & $0 \cdot 3$ & 0.3 & $1 \cdot 2$ & 0.5 & \\
\hline Pteroylglutamate (folate) ( $\mu \mathrm{g})$ & $-2 \cdot 8$ & $1 \cdot 0$ & $40 \cdot 6$ & $36 \cdot 0$ & 0.03 \\
\hline SE & $9 \cdot 1$ & $7 \cdot 5$ & $26 \cdot 4$ & $8 \cdot 3$ & \\
\hline
\end{tabular}

PUFA, polyunsaturated fat; LA, linoleic acid; EPA, eicosapentaenoic acid; MUFA, monounsaturated fat; SFA, saturated fat.

* Unadjusted $P$ value for testing difference between mean changes in continuing smokers and quitters (pooled over men and women).

$\dagger$ One subject was unclassifiable due to missing questionnaire.

† Weight change was not available for one woman quitter and one woman continuing smoker.

confirmed, with two subjects reclassified as continuing smokers. Of the twenty quitters confirmed at 1 year, sixteen were also confirmed at 4 months. Times since quitting were on average slightly lower in men than in women. Mean quit times in men for 4-month and 1-year follow-ups were 10.0 (SE 1.8) weeks and 31.2 (SE 6.0) weeks respectively. The corresponding quit times in women were 13.0 (SE 1.6) weeks and 40.8 (SE 4.2) weeks.

Table 1 shows the general characteristics and mean energy and nutrient intakes of the 301 subjects who completed dietary assessment at recruitment. The mean age was 50 years and approximately half the subjects had non-manual occupations. On average men consumed more energy and had higher intakes of all nutrients than women.

Table 2 shows the observed mean changes in body weight, energy and nutrient intakes between baseline and 4-month follow-up for continuing smokers and quitters. None of the nutrient changes differed significantly by sex, age or occupation. The table shows that in both men and women who continued to smoke there were decreases in intakes of energy and all nutrients between visits except for pteroylglutamate (folate) in women. However, for the quitters there were increases in body weight and intakes of energy and all nutrients except ascorbic acid between visits. For most nutrients the differences in men quitters were 


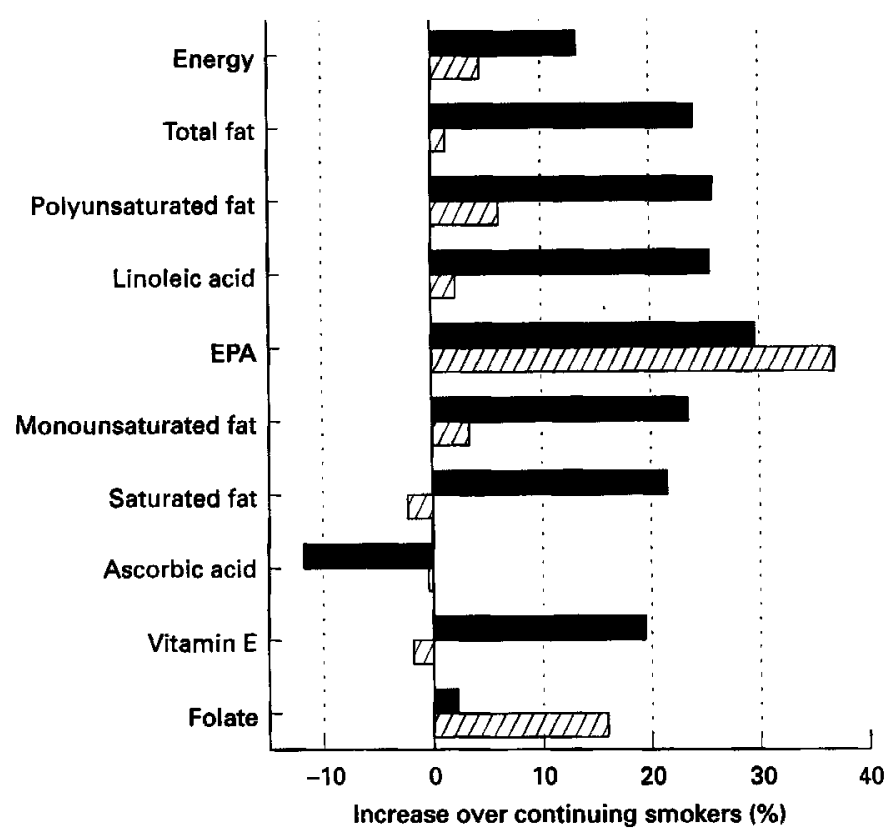

Fig. 1. Percentage dietary changes for quitters compared with continuing smokers after 4 months ( $\boldsymbol{Q})$ or 1 year (B). EPA, eicosapentaenoic acid.

larger than in women quitters. The changes for quitters compared with those who continued to smoke were statistically significant for body weight, energy and all nutrient intakes except for ascorbic acid and folate. After adjustment for change in energy intake, only total fat $(P=0.05)$ and polyunsaturated fatty acids (PUFA) $(P=0.04)$ remained statistically significant.

Table 3 shows the corresponding results for mean changes in nutrient intake between recruitment and the 1-year follow-up. As in Table 2, the continuing smokers reported slightly lower energy and nutrient intakes at follow-up compared with baseline except for folate in women, although the differences were less than those observed at 4 months. For the male quitters, energy intake was higher than at baseline, although less than that observed at 4 months, and intakes of all nutrients other than saturated fat were higher than at baseline. In the female quitters, decreases in energy intake and all nutrients except for eicosapentaenoic acid (EPA) and folate were observed. Results for quitters compared with continuing smokers showed statistically significant increases in weight, and intakes of EPA and folate. Results for EPA and folate remained significant after adjustment for change in energy intake (both $P=0.04$ ). Although changes in EPA intake at both visits were statistically significant, the changes in absolute terms were small. Changes in protein, carbohydrate, sugar, alcohol, non-starch polysaccharide and $\beta$-carotene intake were also analysed but no statistically significant differences by smoking status were found at either follow-up.

Fig. 1 summarizes the percentage changes in energy and all nutrients for quitters compared with continuing smokers between each follow-up and baseline. Percentage changes were in excess of $30 \%$ for EPA at each visit. Increases in the region of $20 \%$ were observed for total fat and specific fats (other than EPA) at first follow-up only. Percentage changes at the 1-year follow-up were small (5\% or less) for energy and all nutrients except for EPA and folate. Weight and EPA intake were the only variables that showed 


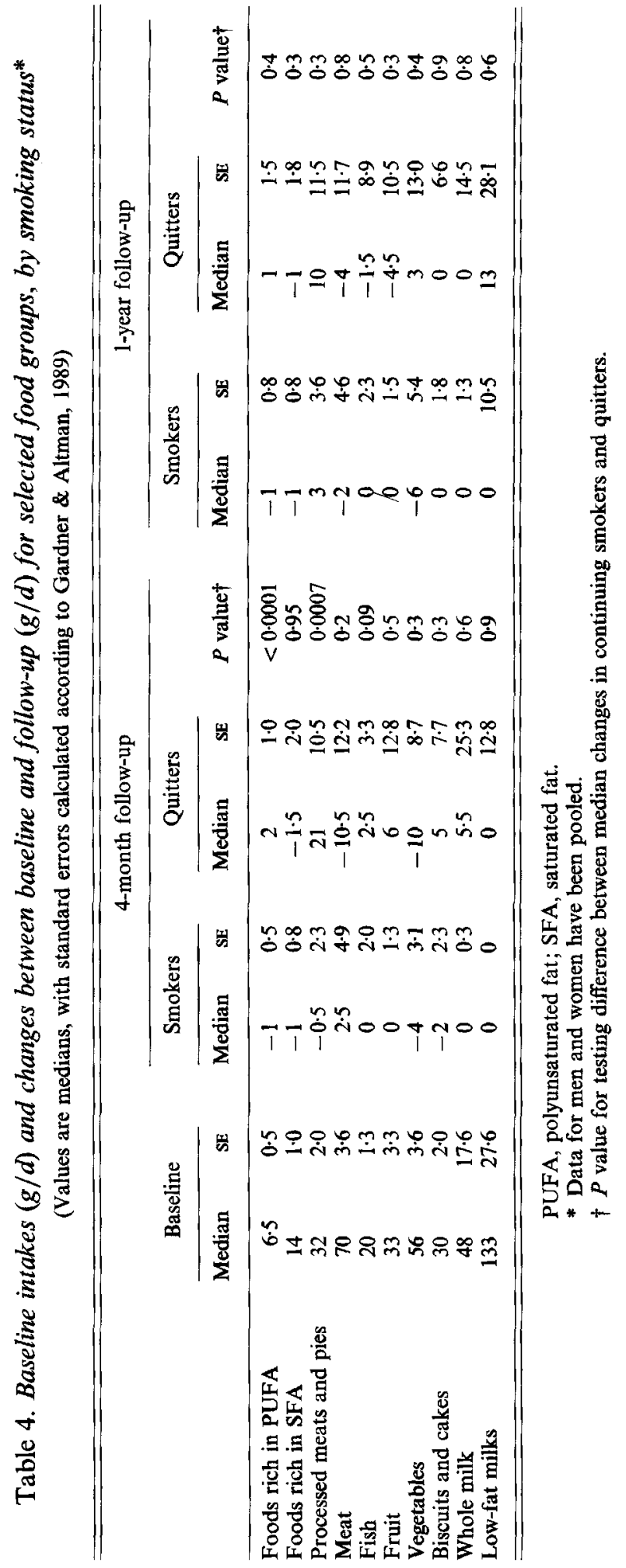


statistically significant increases at both follow-ups, with a larger increase at the 1-year visit than the 4-month visit.

Table 4 examines which food groups contributed to the changes in energy and fat intakes observed after stopping smoking. Results were similar for men and women and therefore the table shows the composite results. At the 4-month follow-up smoking cessation was associated with an increase in consumption of processed meats and pies, and foods rich in polyunsaturated fats. No statistically significant changes in foods rich in saturated fat, meat, fish, vegetables, biscuits and cakes, or milk were detected. At the 1-year follow-up no statistically significant results were observed.

\section{DISCUSSION}

This prospective study of smoking cessation found short-term increases in intakes of energy, total fat and specific types of fat including linoleic acid, and vitamin $E$ on average 10 weeks after quitting smoking in men and 13 weeks in women, but these differences were not sustained in the longer term ( 31 weeks for men and 41 weeks for women) with the exception of higher folate and EPA intakes in quitters compared with those who continued to smoke. So the hypothesis that smoking cessation is associated with an increased consumption of the essential fatty acid linoleic acid is supported for the short term, but as this difference was not sustained the dietary intake of linoleic acid cannot explain the concomitant reduction in risk of coronary disease. Interestingly, in the longer term those who had quit had higher intakes of the major fatty acid in fish (EPA) and this dietary change, although small, could make a minor contribution to the lower risk of coronary disease in ex-smokers.

The quit rates were a little below those originally anticipated with $17 \%$ of returning subjects who completed weighed records quitting at 4 months and $16 \%$ at 1 year. One possible bias in the present study is the low response rate for follow-up, in that those subjects not returning for follow-up may have differed from those returning. The poor response was partly the result of a low rate of attendance and partly the result of a reluctance to repeat the weighed record at follow-up. Of the original 375, 230 subjects $(61 \%)$ returned for the 4-month follow-up and 215 subjects $(57 \%)$ for the 1-year followup. Of those who returned, 153/230 (66\%) completed the weighed records at baseline and follow-up at 4 months and 122/215 (57\%) completed weighed records at baseline and 1 year. Extensive efforts were made to persuade subjects to return for follow-up including home visits, but many smokers returning after completing one weighed record felt that their dietary habits had not changed over the past 4 months or 1 year and did not see the necessity to complete further weighed records. It is possible that some subjects were put off returning for follow-up as they would be asked to complete further weighed records. The great majority $(>95 \%)$ of subjects who did not return for follow-up reported over the telephone that they were still smoking.

In order to determine whether those subjects who returned differed from those who did not, a comparison at baseline was made between subjects who returned and completed further weighed records and those who did not (Thompson, 1993). There were no statistically significant differences in the number of cigarettes smoked/d, body mass index, or occupation group. A comparison of nutrient intakes at baseline showed no difference in energy or nutrient intakes in men. However, those women who returned for follow-up had 10 to $15 \%$ higher energy and nutrient intakes than those who did not return. Therefore there is some indication that in women those who returned may have been different from the non-responders. However, the comparisons between quitters and continuing smokers made in the present paper are amongst those who returned, and are therefore less subject to bias. 
Table 5. Cross-sectional study: differences in nutrient intake by smoking habit*

\begin{tabular}{|c|c|c|c|c|c|}
\hline & \multicolumn{5}{|c|}{ Increase $(\%)$ over never smokers } \\
\hline & \multicolumn{2}{|c|}{ Men } & \multicolumn{2}{|c|}{ Women } & \multirow[b]{2}{*}{$P$ value } \\
\hline & Smokers & Ex-smokers & Smokers & Ex-smokers & \\
\hline Energy & $7 \cdot 0$ & 1.0 & $-4 \cdot 0$ & -7.9 & 0.02 \\
\hline Total fat & $10 \cdot 1$ & $2 \cdot 0$ & 0.8 & $-9 \cdot 5$ & $0-005$ \\
\hline PUFA & $-7 \cdot 7$ & $-1 \cdot 3$ & $-15 \cdot 6$ & $-13 \cdot 6$ & 0.0002 \\
\hline LA & $-11 \cdot 5$ & $-2 \cdot 7$ & $-22 \cdot 5$ & -15.8 & $<0.0001$ \\
\hline EPA & -0.4 & $-1 \cdot 3$ & -9.9 & $-12 \cdot 6$ & 0.8 \\
\hline SFA & 16.5 & 3.6 & $6 \cdot 2$ & $-9 \cdot 1$ & $<0.0001$ \\
\hline Ascorbic acid & $-13 \cdot 4$ & 1.8 & $-13 \cdot 5$ & 0.5 & $<0.0001$ \\
\hline Vitamin $\mathrm{E}$ & -3.4 & -1.8 & $-13 \cdot 9$ & $-8 \cdot 8$ & 0.001 \\
\hline Pteroylglutamate (folate) & $-8 \cdot 7$ & $-2 \cdot 2$ & $-12 \cdot 4$ & $-6 \cdot 3$ & $<0.0001$ \\
\hline
\end{tabular}

PUFA, polyunsaturated fat; LA, linoleic acid; EPA, eicosapentaenoic acid; SFA, saturated fat.

* Modified from Thompson et al. (1993). Differences in body of table are average percentage differences between non-smokers and either smokers or ex-smokers.

$\dagger P$ value is for testing differences between smoking groups after adjustment for age, sex and occupation (manual/non-manual).

At both follow-ups continuing smokers appeared to have increased weight but consumed less energy. This may be due to the subjects keeping less complete weighed records for subsequent diaries. It does not seem to be a result of seasonal variation as appointments were distributed throughout the year. Some subjects, although advised otherwise, used keeping the weighed record as an opportunity to lose weight. The possibility that the decrease in energy is not real is also suggested by dietary data collected on the same sample of smokers using a food-frequency questionnaire which showed no decrease in energy intake with subsequent appointments for continuing smokers ( $R$. L. Thompson, unpublished results). Other studies that have repeated weighed records have also reported a reduction in energy intake with subsequent administrations (Jørgensen et al. 1992; Kristal et al. 1994). However, the effect of lower reported energy intakes with subsequent weighed records would affect both continuing smokers and quitters and therefore should not bias the comparison of the groups.

The baseline data of the cigarette smokers in the present study also constituted part of a cross-sectional dietary survey of cigarette smokers, ex-smokers who had quit for an average of 14 years and never smokers (Thompson et al. 1993). In this study, diet was assessed using a food-frequency questionnaire (Yarnell et al. 1983). This questionnaire had previously been calibrated against the $10 \mathrm{~d}$ weighed record in this population of cigarette smokers (Thompson \& Margetts, 1993). Table 5, modified from Thompson et al. (1993), shows differences in nutrient intakes of smokers and ex-smokers compared with never smokers. These results are consistent with other cross-sectional studies (Thompson et al. 1992) and in addition report data on EPA consumption and smoking status. It shows that male long-term ex-smokers had similar intakes to never smokers but female ex-smokers had lower energy and total fat intakes than never smokers. Based on the results in Table 5 one would expect quitters to show reductions in energy, total fat and saturated fat intakes, and increases in PUFA, linoleic acid, ascorbic acid, vitamin $E$ and folate consumption after stopping smoking.

This is the first study to compare cross-sectional and prospective data from the same population, although dietary assessment methods were different. Many of the short-term 
changes observed in the prospective study, such as the increases in energy, total and saturated fat and EPA, are not consistent with the cross-sectional data, although the increases in PUFA and vitamin $\mathrm{E}$ are. Both the 1-year follow-up and cross-sectional data show increases in folate associated with stopping smoking. However, one would expect a decrease in energy intake in men and women which was not observed in the prospective study. A lack of power partly due to small numbers of subjects quitting smoking and being followed up and small changes in diet at this stage may be responsible for not detecting dietary differences between the quitters and continuing smokers in this prospective study. The power calculations were based on a difference of $3.5 \mathrm{~g}$ in linoleic acid consumption between smokers and non-smokers (Fulton et al. 1988). Other more recent studies have shown differences in linoleic or polyunsaturated fat intakes in the region of $1-2 \mathrm{~g}$ (Fehily et al. 1989; Bolton-Smith et al. 1993; Thompson et al. 1993). If these figures had been used in the power calculations the required sample size would be greatly increased. If the crosssectional data do indicate real changes in diet then it may take longer than 1 year for dietary changes to be complete. This is consistent with the findings of Bolton-Smith et al. (1993) who reported cross-sectional data from the Scottish Heart Health Study which suggest that it may take 4 years of smoking cessation before the general dietary pattern of ex-smokers is similar to that of never smokers.

Other prospective studies of diet and weight change following smoking cessation, mostly relating to changes within a few weeks of quitting, have been reviewed (Thompson et al. 1992). Many studies have shown an increase in body weight after smoking cessation; for example Hall et al. (1989) reported an increase of $2.3 \mathrm{~kg}$ between 8 and 12 weeks after cessation and an increase of $4 \cdot 1 \mathrm{~kg}$ between 22 and 26 weeks after cessation. The effect of smoking cessation on energy intake was reviewed by Perkins (1992) who suggested that increased energy intake is only observed in the first few weeks after smoking cessation but may not persist beyond 1 month. The excess energy appears to come from fat and carbohydrate and may be due to snacks between meals (Stubbe et al. 1982; Rodin, 1987; Hall et al. 1989). There is little information on changes in micronutrient intakes after smoking cessation. Rodin (1987) measured micronutrient intakes but found no change in intake of vitamin $\mathrm{A}$ or ascorbic acid after smoking cessation.

Whilst a reduction in risk of CHD is apparent shortly after giving up smoking, dietary changes appear to take longer to become established. The short-term dietary changes, within 3 months of quitting, are all consistent with inducing a lower risk of coronary disease, particularly the increased intake of linoleic acid. However, these dietary changes are not all sustained over a longer period and within 1 year there is no longer any difference in dietary linoleic acid between those who quit compared with those who continue to smoke, nor for saturated or monounsaturated fats, or antioxidant vitamins. So change in diet does not appear to be a major explanation for the reduction in risk of CHD after quitting smoking with the exception of the fatty acid EPA in fish oil, and dietary folate. As for linoleic acid, there is an inverse relation between EPA and risk of coronary disease (Kromhout et al. 1985; Wood et al. 1987), so the higher longer-term intake of this longchain PUFA may contribute to the lower risk in quitters. Recently Pancharuniti et al. (1994) reported that low plasma folate concentrations increased the risk of coronary artery disease in white men. Men in the highest quartile of plasma folate had a significantly lower odds ratio for early onset coronary artery disease than those in the lowest quartile, 0.4 $(95 \%$ confidence interval $0.3,0.9)$. Smokers have lower serum folate levels than nonsmokers (Heimburger, 1992), possibly because smoking may inactivate folate or folate coenzymes thus increasing the demand for dietary folate. The increase in vitamin $\mathrm{E}$ consumption may be important as there is an imbalance between free-radical production and antioxidant intake in cigarette smokers as a result of the high load of free radicals in 
cigarette smoke and the lower intake of dietary antioxidants, which can lead to oxidative damage and CHD (Duthie et al. 1989). The imbalance between free-radical production and antioxidant intake would be at least partly alleviated by removal of the excess load of free radicals in cigarette smoke by smoking cessation, even if there was no accompanying increase in antioxidants, thus reducing the risk of $\mathrm{CHD}$.

This prospective study shows that changes in dietary habits do occur after smoking cessation, at least in the short term. These short-term changes, however, are not all in the direction suggested by cross-sectional studies of subjects who have quit smoking for a number of years. With the exception of EPA and folate, no dietary changes were observed in subjects at the 1-year follow-up. A possible explanation for the different results from cross-sectional studies and this prospective study is that it may take in excess of 1 year before the diet of quitters approaches that of never smokers. The reduction in risk of CHD within 1 year of quitting smoking does not appear to be explained by dietary changes in terms of saturated fat or the principal component of polyunsaturated fat, linoleic acid, but the higher intakes of EPA and folate could both contribute to the lower risk of coronary disease following smoking cessation.

\section{REFERENCES}

Bolton-Smith, C., Woodward, M., Brown, C. A. \& Tunstall-Pedoe, H. (1993). Nutrient intake by duration of exsmoking in the Scottish Heart Health Study. British Journal of Nutrition 69, 315-352.

Cook, D. G., Shaper, A. G., Pocock, S. J. \& Kussick, S. J. (1986). Giving up smoking and the risk of heart attacks. Lancet ii, $1376-1380$.

Doll, R., Wheatley, K., Gray, R., Sutherland, I. \& Peto, R. (1994). Mortality in relation to smoking; 40 years' observations on male British doctors. British Medical Journal 309, 901-911.

Duthie, G. G., Wahle, K. W. J. \& James, W. P. T. (1989). Oxidants, antioxidants and cardiovascular disease. Nutrition Research Reviews 2, 51-62.

Fehily, A. M., Elwood, P. C. \& Yarnell, J. W. G. (1989), Cigarettes and heart disease. Lancet ii, 114-115.

Fehily, A. M., Phillips, K. M. \& Yarnell, J. W. G. (1984). Diet, smoking, social class, and body mass index in the Caerphilly Heart Disease Study. American Journal of Clinical Nutrition 40, 827-833.

Fulton, M., Thomson, M., Elton, R. A., Brown, S., Wood, D. A. \& Oliver, M. F. (1988). Cigarette smoking, social class and nutrient intake: relevance to coronary heart disease. European Journal of Clinical Nutrition $\mathbf{4 2}$, 797-804.

Gardner, M. J. \& Altman, D. G. (1989). Statistics with Confidence. London: British Medical Journal Publications.

Hall, S. M., McGee, R., Tunstall, C., Duffy, J. \& Benowitz, N. (1989). Changes in food intake and activity after quitting smoking. Journal of Consulting and Clinical Psychology 57, 81-86.

Heimburger, D. C. (1992). Localized deficiencies of folic acid in aerodigestive tissues. Annals of the New York Academy of Sciences 669, 87-96.

Jørgensen, L. M., Isaksson, B. \& Schroll, M. (1992). Reproducibility and validity of 7-day food records. European Journal of Clinical Nutrition 46, 729-734.

Kristal, A. R., Beresford, S. A. A. \& Lazovich, D. (1994). Assessing change in diet-intervention research. American Journal of Clinical Nutrition 59, 185S-189S.

Kromhout, D., Bosschieter, E. B. \& Coulander, C. de L. (1985). The inverse relation between fish consumption and 20-year mortality from coronary heart disease. New England Journal of Medicine 312, 1205-1209.

Margetts, B. M. \& Jackson, A. A. (1993). Interactions between people's diet and their smoking habits: the dietary and nutritional survey of British adults. British Medical Journal 307, 1381-1384.

Office of Population Censuses and Surveys (1980). Classification of Occupations. London: H.M. Stationery Office.

Pancharunti, N., Lewis, C. A., Sauberlich, H. E., Perkins, L. L., Rodney, C. P. G., Alvarez, J. O., Macaluso, M., Acton, R. T., Copeland, R. B., Cousins, A. L., Gore, T. B., Cornwell, P. E. \& Roseman, J. M. (1994). Plasma homocyst(e)ine, folate, and vitamin B-12 concentrations and risk of early-onset coronary artery disease. American Journal of Clinical Nutrition 59, 940-948.

Perkins, K. A. (1992). Effects of tobacco smoking on caloric intake. British Journal of Addiction 87, $193-205$.

Rodin, J. (1987). Weight change following smoking cessation: the role of food intake and exercise. Addictive Behaviours 12, 303-317.

Stubbe, I., Eskilsson, J. \& Nilsson-Ehle, P. (1982). High density lipoprotein concentrations increase after stopping smoking. British Medical Journal 284, 1511-1513.

Subar, A. F., Harlan, L. C. \& Mattson, M. E. (1990). Food and nutrient intake differences between smokers and non-smokers in the US. American Journal of Public Health 80, 1323-1329. 
Thompson, R. L. (1993). Methodological considerations in assessing food and nutrient intakes in cigarette smokers. PhD Thesis, University of Southampton.

Thompson, R. L. \& Margetts, B. M. (1993). Comparison of a food frequency questionnaire with a 10-day weighed record in cigarette smokers. International Journal of Epidemiology 22, 824-833.

Thompson, R. L., Margetts, B. M., Wood, D. A. \& Jackson, A. A. (1992). Cigarette smoking and food and nutrient intakes in relation to coronary heart disease. Nutrition Research Reviews 5, 131-152.

Thompson, R. L., Pyke, S., Scott, E. A., Thompson, S. G. \& Wood, D. A. (1993). Cigarette smoking, polyunsaturated fats, and coronary heart disease. Annals of the New York Academy of Sciences 686, 130-139.

Whichelow, M. J., Erzinclioglu, S. W. \& Cox, B. D. (1991). A comparison of the diets of non-smokers and smokers. British Journal of Addiction 86, 71-81.

Wood, D. A., Butler, S., Riemersma, R. A., Thomson, M., Macintyre, C., Elton, R. A. \& Oliver, M. F. (1987). Linoleic and eicosapentaenoic acids in adipose tissue and platelets and risk of coronary heart disease. Lancet i, $177-183$.

Wood, D. A. \& Oliver, M. F. (1992). Linoleic acid, antioxidant vitamins and coronary heart disease. In Coronary Heart Disease Epidemiology: From Aetiology to Public Health, pp. 179-202 [M. Marmot and P. Elliott, editors]. Oxford: Oxford University Press.

Yarnell, J. W. G., Fehily, A. M., Milbank, J. E., Sweetnam, P. M. \& Walker, C. L. (1983). A short dietary questionnaire for use in an epidemiological survey: comparison with weighed dietary records. Human Nutrition: Applied Nutrition 37A, 103-112. 